\title{
Community analysis of biofilms on flame- oxidized stainless steel anodes in microbial fuel cells fed with different substrates
}

\author{
Nweze Julius Eyiuche ${ }^{1,2}$, Shiho Asakawa ${ }^{3}$, Takahiro Yamashita ${ }^{4}$, Atsuo Ikeguchi ${ }^{3}$, Yutaka Kitamura ${ }^{1}$ \\ and Hiroshi Yokoyama ${ }^{4^{*}}$ (D)
}

\begin{abstract}
Background: The flame-oxidized stainless steel anode (FO-SSA) is a newly developed electrode that enhances microbial fuel cell (MFC) power generation; however, substrate preference and community structure of the biofilm developed on FO-SSA have not been well characterized. Herein, we investigated the community on FO-SSA using high-throughput sequencing of the $16 \mathrm{~S}$ rRNA gene fragment in acetate-, starch-, glucose-, and livestock wastewater-fed MFCs. Furthermore, to analyze the effect of the anode material, the acetate-fed community formed on a common carbon-based electrode — carbon-cloth anode (CCA)—was examined for comparison.
\end{abstract}

Results: Substrate type influenced the power output of MFCs using FO-SSA; the highest electricity was generated using acetate as a substrate, followed by peptone, starch and glucose, and wastewater. Intensity of power generation using FO-SSA was related to the abundance of exoelectrogenic genera, namely Geobacter and Desulfuromonas, of the phylum Proteobacteria, which were detected at a higher frequency in acetate-fed communities than in communities fed with other substrates. Lactic acid bacteria (LAB)—Enterococcus and Carnobacterium - were predominant in starch- and glucose-fed communities, respectively. In the wastewater-fed community, members of phylum Planctomycetes were frequently detected (36.2\%). Exoelectrogenic genera Geobacter and Desulfuromonas were also detected in glucose-, starch-, and wastewater-fed communities on FO-SSA, but with low frequency (0-3.2\%); the lactate produced by Carnobacterium and Enterococcus in glucoseand starch-fed communities might affect exoelectrogenic bacterial growth, resulting in low power output by MFCs fed with these substrates. Furthermore, in the acetate-fed community on FO-SSA, Desulfuromonas was abundant (15.4\%) and Geobacter had a minor proportion (0.7\%), while in that on CCA, both Geobacter and Desulfuromonas were observed at similar frequencies (6.0-9.8\%), indicating that anode material affects exoelectrogenic genus enrichment in anodic biofilm.

Conclusions: Anodic community structure was dependent on both substrate and anode material. Although Desulfuromonas spp. are marine microorganisms, they were abundant in the acetate-fed community on FO-SSA, implying the presence of novel non-halophilic and exoelectrogenic species in this genus. Power generation using FO-SSA was positively related to the frequency of exoelectrogenic genera in the anodic community. Predominant $\angle A B$ in saccharide-fed anodic biofilm caused low abundance of exoelectrogenic genera and consequent low power generation.

Keywords: Community structure, Flame oxidation, Geobacter, Desulfuromonas, Microbial fuel cell, Stainless steel anode

\footnotetext{
* Correspondence: hiroshiy@affrc.go.jp

${ }^{4}$ Division of Animal Environment and Waste Management Research, Institute

of Livestock and Grassland Science, National Agriculture and Food Research

Organization (NARO), 2 Ikenodai, Tsukuba 305-0901, Japan

Full list of author information is available at the end of the article
} 


\section{Background}

The microbial fuel cell (MFC) is a bioelectrochemical device that directly generates electricity by oxidation of organic matter under anaerobic conditions [1-3]. Anodes based on carbon materials such as carbon cloth, carbon fiber, carbon nanotubes, and graphene have been widely used in MFCs as a result of their specific surface area, chemical stability, and biocompatibility [4]. However, metal and metal-oxide-based anodes are not used frequently because of low electrical output. Recently, a new method that oxidizes the surface of stainless steel anodes (SSA) with flame has been reported to improve current output in bioelectrochemical systems [5] and power generation in MFCs [6]. The maximum power density using flame-oxidized (FO) SSA in MFCs was $24 \%$ higher than that of a common carbon-based electrode, carbon-cloth anode (CCA) [6]. FO-SSA can be easily prepared, and stainless steel is inexpensive, highly conductive, and chemically and physically strong. Flame oxidation leads to the formation of Fe-oxide nanoparticles on the SSA surface, and the particles formed have been suggested to gather exoelectrogenic and Fe-oxide reducing bacteria onto the surface [6].

Microorganisms adhere to the anodic surface in MFCs, and some of the bacterial species, called exoelectrogenic bacteria [7], among the adherent microorganisms can transfer electrons from organic matter to the anode, via several electron-transfer pathways, such as direct transfer through membrane-bound c-type cytochrome [8], transfer using conductive pili [9], and self-mediated transfer via endogenous redox-active metabolites [10]. Geobacter species are well-characterized exoelectrogenic bacteria in the phylum Proteobacteria [11], and are $\mathrm{Fe}(\mathrm{III})$-oxide reducing bacteria, found in a variety of anoxic subsurface environments [12]. Geobacter has been demonstrated to generate current by pathways involving direct electron transfer and pili $[8,9]$. Many exoelectrogenic bacteria including Geobacter can directly produce current from acetate without cooperation from other bacteria [13]. However, when complex substrates, such as glucose, starch, cellulose, proteins, and organic matter present in wastewater, are fed to MFCs, nonexoelectrogenic bacteria decompose them into simple substrates that are available to exoelectrogenic bacteria. The non-exoelectrogenic bacteria are crucial for efficient electricity generation from complex substrates.

As the performance of MFCs depends on the kind of microorganisms present in the anodic biofilm, it is important to understand the mechanism of community-structure formation. The substrate preference and community structure for the biofilm developed on carbon-based anodes have been well studied [13-15]. However, as the flame-oxidation technique was developed recently, the dependency of community structure on the type of substrate has not been examined for FO-SSA. The kinds of exoelectrogenic bacteria preferentially enriched in the FOSSA biofilm are unknown. Next-generation sequencing technology is a powerful tool for analyzing bacterial community structure at extremely fine resolution [16]. High-throughput sequencing analyzes several million reads for the $16 \mathrm{~S}$ rRNA gene, by which slight differences between bacterial community structures can be detected. In the present study, the communities on FOSSA fed with defined substrates and livestock wastewater were investigated by high-throughput sequencing. To analyze the effect of the anode material, the community formed on the standard carbonaceous electrode, CCA, fed with acetate was also examined.

\section{Methods}

\section{MFC operation and power density}

FO-SSA was made from a 0.2-mm thick mesh (100 mesh, SUS304, $100-\mu \mathrm{m}$ wire diameter) by flame oxidation as described previously [6]. The FO-SSA $(4 \mathrm{~cm} \times 80 \mathrm{~cm})$ was folded and placed in a single-chambered air-cathode MFC reactor [17]. The MFC was cubic in shape with an inner volume of $125 \mathrm{~mL}(5 \mathrm{~cm} \times 5 \mathrm{~cm} \times 5 \mathrm{~cm})$, fabricated with $0.8 \mathrm{~cm}$ thick polycarbonate resin. A carbon-paper cathode containing $0.5 \mathrm{mg} / \mathrm{cm}^{2}$ of Pt catalyst was placed on one side of the MFC. The reactor configuration and electrode sizes were the same as the membrane-less MFCs used in the previous study [6]. Livestock wastewater and a basal medium supplemented with $2 \mathrm{~g} / \mathrm{L}$ glucose or soluble starch were fed to the MFCs. The basal medium contained per liter: $1 \mathrm{~g}$ meat extract, $0.3 \mathrm{~g}$ urea, $0.6 \mathrm{~g} \mathrm{NaH}_{2-}$ $\mathrm{PO}_{4} \cdot 2 \mathrm{H}_{2} \mathrm{O}, 2 \mathrm{~g} \mathrm{NaHCO}, 0.12 \mathrm{~g} \mathrm{NaCl}, 0.05 \mathrm{~g} \mathrm{KCl}, 0.03 \mathrm{~g}$ $\mathrm{CaCl}_{2} \cdot 2 \mathrm{H}_{2} \mathrm{O}$, and $0.05 \mathrm{~g} \mathrm{MgSO}_{4} \cdot 7 \mathrm{H}_{2} \mathrm{O}$. Wastewater with a $1000-1500 \mathrm{mg} / \mathrm{L}$ biochemical oxygen demand was collected from the cattle and swine barns at the Institute of Livestock and Grassland Science, NARO (Tsukuba-city, Ibaraki, Japan). Activated sludge sampled at a wastewatertreatment plant in the Institute was inoculated into all the MFCs as the seed sludge. The MFCs were operated at $30{ }^{\circ} \mathrm{C}$ in a fed-batch mode. The MFCs were connected to a $4.3 \mathrm{k} \Omega$ external resistor, and the resistance value was decreased stepwise to $1.1 \mathrm{k} \Omega$ and $0.36 \mathrm{k} \Omega$ during operation. For comparison, a CCA with a size of $5 \mathrm{~cm} \times 5 \mathrm{~cm}$ was placed opposite the cathode in the cubic MFC reactor, and the activated sludge was inoculated. The MFC equipped with CCA was fed with basal medium containing $2 \mathrm{~g} / \mathrm{L}$ sodium acetate, and was operated in the same manner as the MFCs with FO-SSA. After accumulation culture for 6-8 weeks, the electrical power of the MFCs was determined using a potentiostat/galvanostat, as described previously [6]. The power density was normalized with respect to the projectedcathode area $\left(\mathrm{m}^{2}\right)$. 
High-throughput sequencing and taxonomic assignment Next-generation sequencing was performed with the MiSeq Illumina sequencing platform (Illumina Inc., CA, USA) targeting the V3-V4 region of the $16 \mathrm{~S}$ rRNA gene [16]. The anodes were thoroughly washed with distilled water and then cut into small pieces. Genomic DNA of the biofilms was extracted from the anode pieces using an UltraClean ${ }^{\mathrm{TM}}$ Soil DNA Isolation kit (Mo Bio Laboratories, Carlsbad, CA, USA). Libraries were constructed through PCR using the primers with the Illumina overhang adapter sequences, 357F (5' -TCG TCG GCA GCG TCA GAT GTG TAT AAG AGA CAG CCT ACG GGN GGC WGC AG-3') and 802R (5'-GTC TCG TGG GCT CGG AGA TGT GTA TAA GAG ACA GTA CNV GGG TAT CTA ATC C-3'), as specified by the manufacturer's instructions. PCR products were purified using an AMPure XP kit (Beckman Coulter, Miami, FL, USA) and were quantified for equimolar pooling by using a NanoDrop ${ }^{\mathrm{TM}}$ spectrophotometer (Thermo Fisher Scientific, Waltham, MA, USA). The libraries were sequenced on a 300PE MiSeq run, and image analysis, base calling, and data quality assessment were performed with the MiSeq Reporter software (Illumina). Paired-end read data exported in FASTQ format were joined and qualitychecked with the Quantitative Insights Into Microbial Ecology (QIIME) software ver. 1.8 [18]. The joined read sequences were clustered into operational taxonomic units (OTUs) at a similarity threshold of $97 \%$ by using the Uclust method [19] with the Greengenes reference database [20] and the QIIME script "pick_open_reference_ otus.py". Singletons were removed with the script. Representative sequences were aligned using PyNAST [21], and a phylogenetic tree was constructed. The taxonomic classification and alpha and beta diversities were computed using QIIME. The taxonomic assignment of the major OTUs was checked using BLAST and Classifier [22]. The beta diversity was calculated using a weighted UniFrac distance matrix [23], and the result was visualized using a principal coordinate (PCo) plot. The phylogenetic tree, combined with the heat map, was calculated by the unweighted pair-group method using arithmetic averages (UPGMA) using MEGA4 [24]. The sequencing data of representative OTUs and all reads were deposited in DDBJ under accession numbers LC209094-LC209102 and DRR090365DRR090369 (Sequence Read Archive), respectively.

\section{Results and discussion}

\section{Electricity generation from different substrates}

To examine the effect of substrates on production of current by FO-SSA, two kinds of defined substrate, glucose and starch, and livestock wastewater were fed to the MFCs. Two MFC reactors were operated for each substrate, and power density was measured once per reactor. The MFCs fed with starch and glucose generated similar levels of maximum power density, $615-704 \mathrm{~mW} / \mathrm{m}^{2}$ (average $660 \mathrm{~mW} / \mathrm{m}^{2}$ ) and 614-650 $\mathrm{mW} / \mathrm{m}^{2}$ (average $632 \mathrm{~mW} / \mathrm{m}^{2}$ ), respectively (Fig. 1 and Table 1). Livestock wastewater consists of complex substrates and large amounts of non-electrogenic microorganisms that compete with exoelectrogenic bacteria for substrate utilization. Thus, compared with the values for MFCs with starch and glucose, the maximum power density of the MFCs with wastewater was approximately half, 236-419 $\mathrm{mW} / \mathrm{m}^{2}$ (average $328 \mathrm{~mW} / \mathrm{m}^{2}$ ). Furthermore, cathode performance considerably affects the power generation of MFCs; consequently, heterogeneity in power generation was observed between the two MFCs fed with the same substrate owing to the slightly non-uniform coating of the Pt-catalyst on the cathode surface.

We previously reported that the maximum power density using FO-SSA was $1063 \mathrm{~mW} / \mathrm{m}^{2}$ for acetate and $798 \mathrm{~mW} / \mathrm{m}^{2}$ for peptone [6]. These values are higher than those observed for starch, glucose, and wastewater. Therefore, substrate type influenced the power output using FO-SSA, and the preferred substrate for the biofilm on FO-SSA was acetate, followed by peptone, then starch and glucose (equal), and finally wastewater. This substrate preference is similar to that of biofilm formed on carbon-based anodes [13]. Furthermore, these results demonstrated that generation of electricity using FO-SSA was possible from livestock wastewater, although the intensity was lower than that from defined substrates.

\section{Community structure of biofilm developed on FO-SSA}

We previously reported the community structure on FO-SSA fed with peptone [6], but we not did examine the same for FO-SSA fed with acetate. Thus, in this study, the biofilm on FO-SSA fed with acetate, glucose, starch, and livestock wastewater was analyzed by high

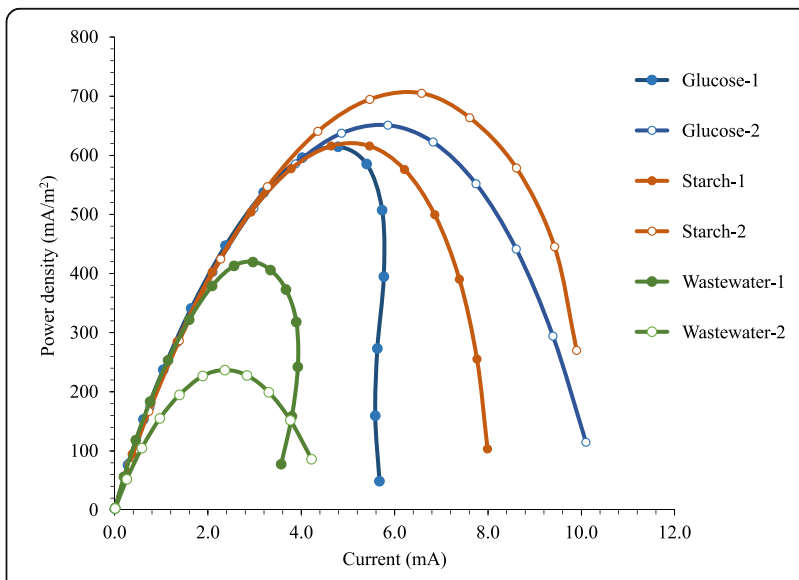

Fig. 1 Power density of the MFCs equipped with FO-SSA using different substrates as fuel. Two reactors were operated for each substrate 
Table 1 Experimental conditions for different anodic biofilms in the microbial fuel cells and their power output

\begin{tabular}{|c|c|c|c|c|c|}
\hline & GM-FO-SSA & SM-FO-SSA & WW-FO-SSA & AM-FO-SSA & AM-CCA \\
\hline Substrate & Glucose & Soluble starch & Livestock wastewater & Acetate & Acetate \\
\hline Anode material & $\begin{array}{l}\text { Flame-oxidized stainless } \\
\text { steel mesh (SUS304) }\end{array}$ & $\begin{array}{l}\text { Flame-oxidized stainless } \\
\text { steel mesh (SUS304) }\end{array}$ & $\begin{array}{l}\text { Flame-oxidized stainless } \\
\text { steel mesh (SUS304) }\end{array}$ & $\begin{array}{l}\text { Flame-oxidized stainless } \\
\text { steel mesh (SUS304) }\end{array}$ & Carbon cloth \\
\hline Inoculum & Activated sludge & Activated sludge & Activated sludge & Activated sludge & Activated sludge \\
\hline $\begin{array}{l}\text { Maximum power } \\
\text { density }\left(\mathrm{mW} / \mathrm{m}^{2}\right)\end{array}$ & 632 & 660 & 328 & $1,063^{\mathrm{a}}$ & 310 \\
\hline
\end{tabular}

Abbreviations: FO-SSA flame-oxidized stainless steel anode, CCA carbon-cloth anode, AM acetate medium, SM starch medium, GM glucose medium, $W W$ wastewater

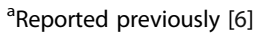

throughput sequencing targeting an amplified 16S rRNA gene fragment. Operational conditions for the acetate-fed MFCs with FO-SSA were the same as those for MFCs fed with other substrates. In addition, to investigate the influence of the anode material, the biofilm formed on the common carbon-based anode (CCA) fed with acetate was also analyzed; the MFC with CCA produced the maximum power density of $310 \mathrm{~mW} / \mathrm{m}^{2}$. Animal manure is known to contain various kinds of useful bacteria including exoelectrogens, hydrogen-producing bacteria, and methanogens for anaerobic digestion $[25,26]$, and the activated sludge from animal manure treatment that was inoculated as the seed sludge into all MFCs was identical.

In total, 239,571 sequencing reads were generated, and the reads were grouped into 3043 OTUs. The OTU distribution and alpha diversity indexes of the communities are shown in Table 2. The range of alpha diversity was 1200 2300 for Chao1 richness and 5.6-7.9 for Shannon's diversity index. While Good's coverage was more than 0.98 in all the communities, none of the rarefaction curves reached a plateau (Fig. 2a). In the beta diversity analysis, the community structure on FO-SSA with acetate was the closest to that of CCA with acetate in the principal coordinate (PCo) plot (Fig. 2b), and was distinct from the other communities, suggesting that the overall structures of the acetate-fed communities on FO-SSA and CCA were similar. The community on FO-SSA with starch was close to that of glucose in the plot. The similarity between the community structures for starch and glucose seems to be reasonable, since glucose is a product of starch hydrolysis.
All communities were dominated by representatives of six phyla: Firmicutes, Planctomycetes, Proteobacteria, Bacteroidetes, Synergistetes, and Parcubacteria (Fig. 3). The three phyla Proteobacteria, Firmicutes, and Bacteroidetes are frequently observed in MFCs [27]. Proteobacteria including electrogenic and Fe(III)oxide reducing bacteria such as Geobacter were detected at a high frequency $(18.9-19.8 \%)$ in the acetatefed communities, while the abundance of the phylum was low (5.4-6.2\%) in the other communities. Firmicutes including saccharolytic anaerobes such as Clostridium were abundant (40.6-51.0\%) in the glucose- and starchfed communities, as compared to the other communities (15.3-17.1\%). In the wastewater-fed community, the most predominant phylum was Planctomycetes (36.2\%). A Planctomycetes-dominant biofilm was reported in an anodic biofilm of a bioelectrochemical system that was fed with livestock wastewater [28]. Although there are no known exoelectrogenic members in Planctomycetes, the Planctomycetes-dominant structure might be a feature of the exoelectrogenic community resulting from feeding with livestock wastewater.

\section{Effect of substrate and anodic material on exoelectrogenic bacteria}

Two exoelectrogenic genera, Geobacter and Desulfuromonas, were detected by the genus-level analysis (Fig. 4). Both genera belong to the same order Desulfuromonadales within the phylum Proteobacteria. Desulfuromonas was abundant $(15.4 \%)$ in the community on FO-SSA fed

Table 2 Number of reads and alpha diversity index for the anodic-biofilm communities in microbial fuel cells fed with different substrates

\begin{tabular}{lllllll}
\hline Sample & No. of reads & No. of OTUs & Chao1 richness & Shannon's diversity index & Abundance-based coverage estimator & Good's coverage \\
\hline AM-CCA & 86,298 & 1645 & 1951 & 7.475 & 1956 & 0.996 \\
AM-FO-SSA & 58,305 & 1249 & 1486 & 6.818 & 1504 & 0.995 \\
SM-FO-SSA & 26,190 & 1002 & 1294 & 5.646 & 1333 & 0.988 \\
GM-FO-SSA & 48,481 & 1838 & 2282 & 6.963 & 2323 & 0.989 \\
WW-FO-SSA & 18,819 & 1303 & 1513 & 7.84 & 1546 & 0.983 \\
\hline
\end{tabular}

Abbreviations: OUT operational taxonomic units, FO-SSA flame-oxidized stainless steel anode, CCA carbon-cloth anode, AM acetate medium, SM starch medium, GM glucose medium, WW wastewater 


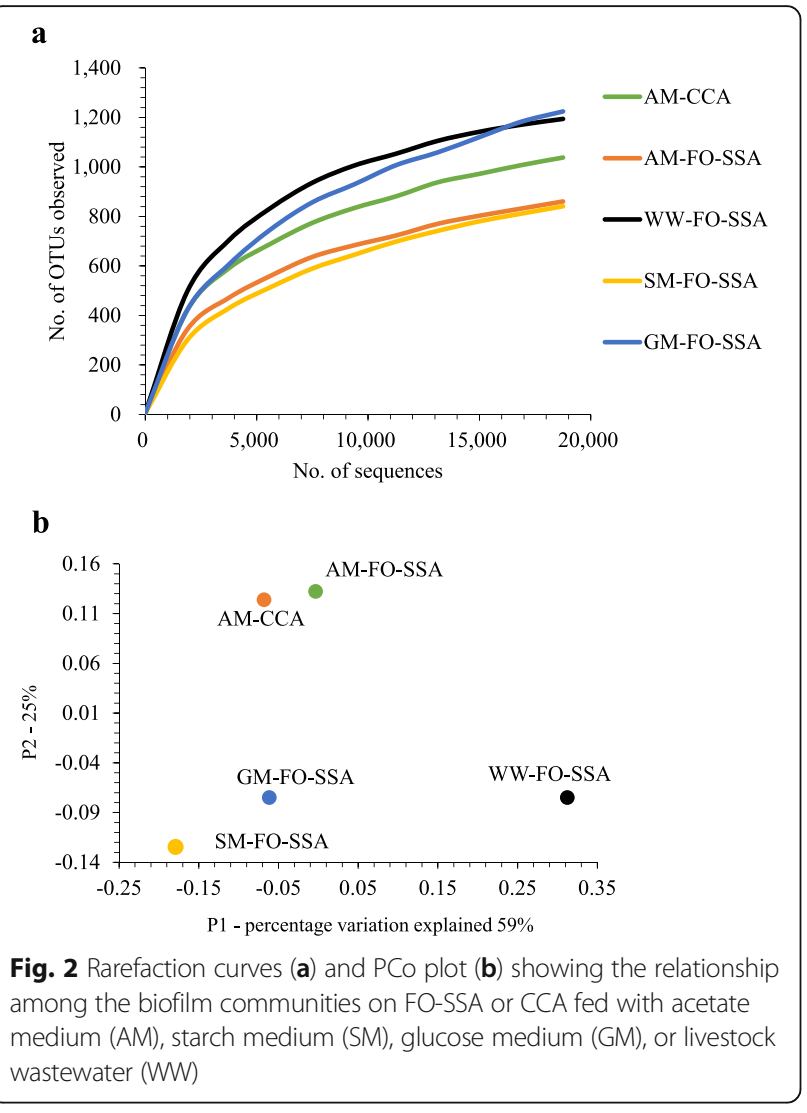

with acetate, while Geobacter was minor (only $0.7 \%$ ). In the community on CCA with acetate, both Geobacter and Desulfuromonas were observed at similar abundant frequencies $(6.0-9.8 \%)$. This result indicates that exoelectrogenic genus enrichment in anodic biofilm is dependent on the anode material used. Desulfuromonas species are marine anaerobes that reduce sulfur [29] and Fe(III) oxide [30] coupled with acetate oxidation. Desulfuromonas acetoxidans and 'Desulfuromonas soudanensis' produce electric current using acetate [31, 32]. Desulfuromonas is frequently enriched in anodic biofilms using saline medium due to its halophilic characteristics [33], but is infrequently enriched with a conventional low-salt medium. Geobacter is a common exoelectrogenic genus that is enriched with low-salt medium. Although the low-salt medium was used in this study, it is interesting to note that Desulfuromonas was more predominant than Geobacter in the community on FO-SSA fed with acetate. OTUs affiliated with Desulfuromonas showed 91-96\% identity in DNA sequence to D. acetoxidans and D. soudanensis (Fig. 5). The bacteria corresponding to the OTUs are inferred to be novel exoelectrogenic species in the genus Desulfuromonas, since the bacteria are not halophilic, which is an important feature of the genus. The major difference between FO-SSA and CCA is the presence or absence of Fe oxide on the surface. The Desulfuromonas bacteria could apparently take advantage of Fe oxide more proficiently, resulting in greater abundance in comparison with Geobacter in the acetate-fed community on FO-SSA.

The electrogenic genera Geobacter and Desulfuromonas were also detected in the communities on FO-SSA fed with glucose, starch, and wastewater, but the frequency was low $(0-3.2 \%)$. This result is consistent with the data of low power output by the MFCs fed with these substrates. The predominant genera in the communities from feeding with starch and glucose were Enterococcus (33.7\%) and Carnobacterium (24.9\%), respectively. They are lactic acid bacteria (LAB) that produce lactic acid from saccharides. OTUs affiliated with Enterococcus showed 99\% identity to the amylolytic bacterium Enterococcus faecium that produces lactic acid directly from starch [34]. As LAB are fermentative bacteria, current production is not needed for their growth in MFCs. Geobacter sulfurreducens was reported to produce current from lactate, but the intensity was lower than that from acetate [35]. Current production from lactate is not reported for the other Geobacter and Desulfuromonas species, while several Geobacter species

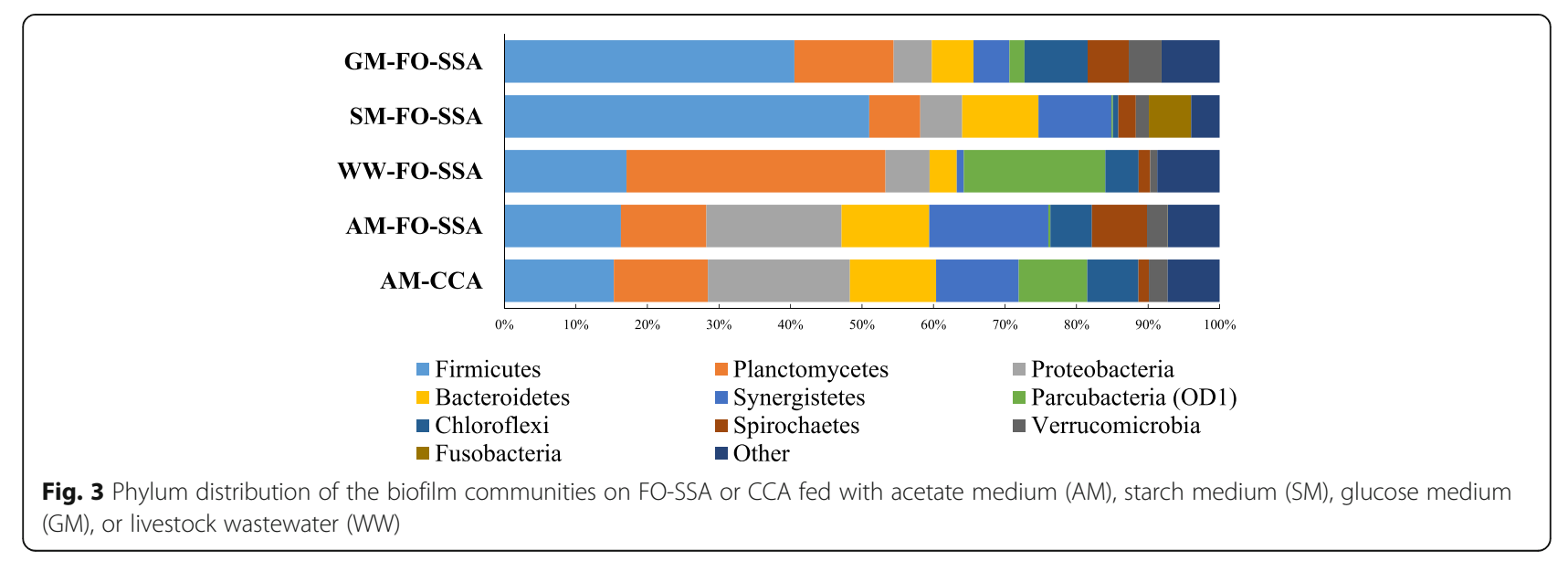




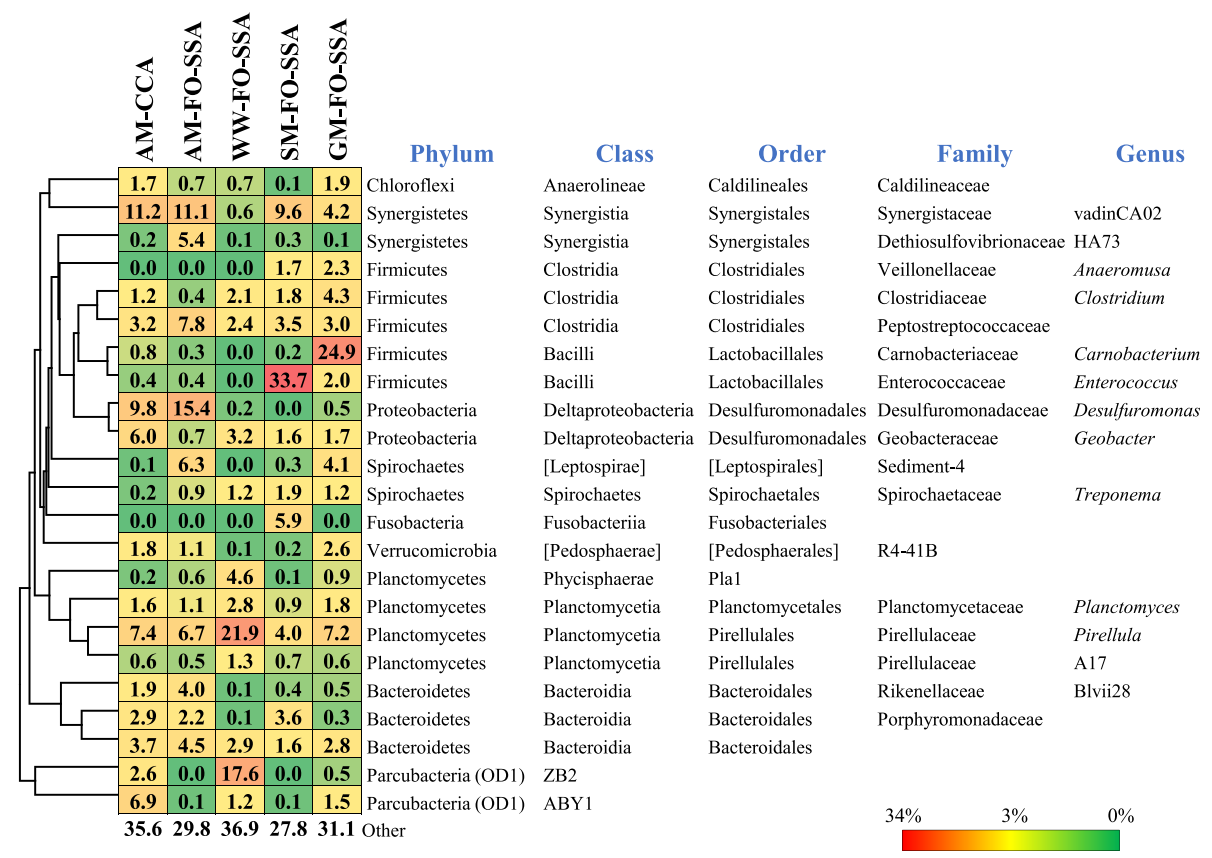

Fig. 4 Phylogenetically clustered heat map of representative genera of biofilm communities on FO-SSA or CCA fed with acetate medium (AM), starch medium (SM), glucose medium (GM), or livestock wastewater (WW)

oxidize lactate coupled with $\mathrm{Fe}(\mathrm{III})$-oxide reduction [36]. Generally, acetate is thought to be a more preferred substrate than lactate for current production in MFCs $[13,15]$. These observations suggest that the exoelectrogenic bacteria cannot grow fast in the communities fed with glucose and starch, since the lactate produced by Carnobacterium and Enterococcus is not the best substrate for them. In the community on FO-SSA fed with peptone [6], Geobacter was detected at a high frequency (8.8-9.2\%), while the frequency of Desulfuromonas was low. A putative

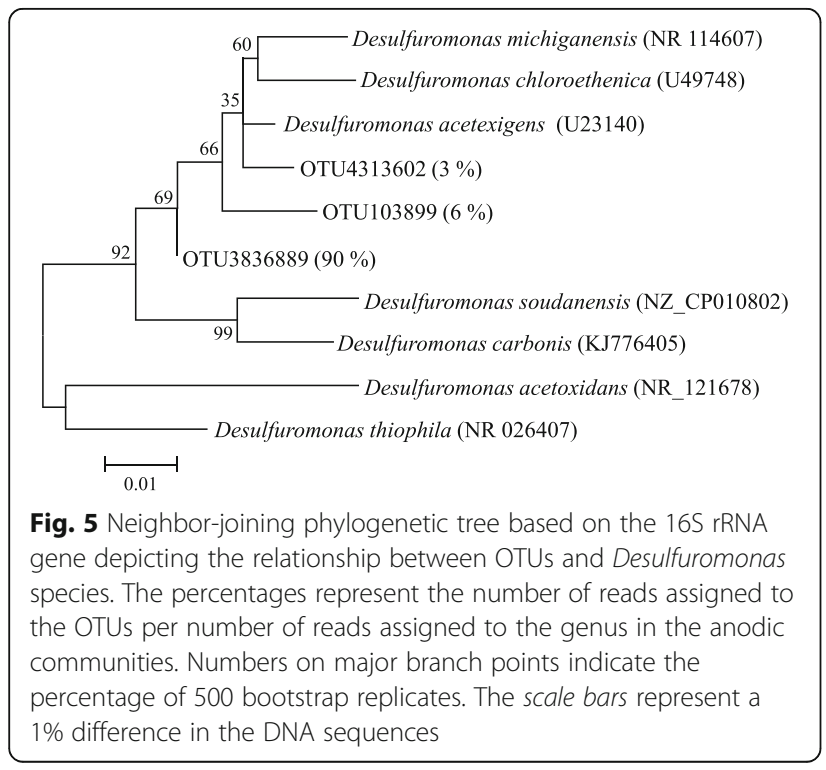

non-saccharolytic genus that produced acetate from amino acids was most predominant $(>30 \%)$ in the peptone-fed community. The acetate produced by the genus is thought to serve as the fuel for current production by Geobacter, and thus the power output of the peptone-fed MFCs could be higher than that of MFCs fed with glucose and starch. The results of the present study showed that the community structure on FO-SSA depended on the substrate used, and that the intensity of power generation using FO-SSA was positively correlated with the abundance of exoelectrogenic bacteria in the anodic community.

\section{Conclusions}

The community structure of the anodic biofilm in MFCs was dependent on both the substrate and anode material used. Based on combining the results of this study with previous work [6], acetate was the most preferred substrate for the biofilm on FO-SSA. The order of substrate preference was: acetate $>$ peptone $>$ starch $=$ glucose > wastewater. The intensity of power generation using FO-SSA was positively related to the abundance of exoelectrogenic genera in the phylum Proteobacteria. Novel non-halophilic and exoelectrogenic species in the genus Desulfuromonas were apparently present in the biofilm on FO-SSA fed with acetate. LAB became predominant in the community fed with the saccharides (glucose and starch), and the lactate produced seemed to be of low availability to the exoelectrogenic genera, resulting in low power output with these saccharide substrates. 


\section{Abbreviations}

CCA: Carbon-cloth anode; FO-SSA: Flame-oxidized SSA; LAB: Lactic acid bacteria; MFC: Microbial fuel cell; PCo: Principal coordinate; SSA: Stainless steel anode

\section{Acknowledgements}

We thank Ms. Kyoko Hirano for her skillful assistance with the experiments.

\section{Funding}

This study was supported in part by the Japan Society for the Promotion of Science (JSPS) under KAKENHI (JP26850177 and JP15K07820).

\section{Availability of data and materials}

The OTU sequences were deposited in DDBJ (accession numbers LC209094LC209102).

\section{Authors' contributions}

$\mathrm{SA}, \mathrm{TY}$, and $\mathrm{Al}$ analyzed the electricity production data. NJE, YK, and HY characterized the community structures. All the authors have read and approved the final manuscript.

\section{Competing interests}

The authors declare that they have no competing interests.

\section{Consent for publication}

Not applicable

\section{Ethics approval and consent to participate}

Not applicable

\section{Publisher's Note}

Springer Nature remains neutral with regard to jurisdictional claims in published maps and institutional affiliations.

\section{Author details}

'Graduate School of Life and Environmental Sciences, University of Tsukuba, 1-1-1 Tennodai, Tsukuba, Ibaraki 305-8572, Japan. ²Department of Microbiology, University of Nigeria, Nsukka, Enugu State 400241, Nigeria. ${ }^{3}$ Faculty of Agriculture, Utsunomiya University, 350 Minemachi, Utsunomiya 321-8505, Japan. ${ }^{4}$ Division of Animal Environment and Waste Management Research, Institute of Livestock and Grassland Science, National Agriculture and Food Research Organization (NARO), 2 Ikenodai, Tsukuba 305-0901, Japan.

Received: 30 January 2017 Accepted: 18 June 2017

Published online: 29 June 2017

\section{References}

1. Rabaey K, Verstraete W. Microbial fuel cells: novel biotechnology for energy generation. Trends Biotechnol. 2005;23(6):291-8.

2. Logan BE, Regan JM. Electricity-producing bacterial communities in microbial fuel cells. Trends Microbiol. 2006;14:512-8.

3. Lovley DR. Microbial fuel cells: novel microbial physiologies and engineering approaches. Curr Opin Biotechnol. 2006:17(3):327-32.

4. Wei J, Liang P, Huang X. Recent progress in electrodes for microbial fuel cells. Bioresour Technol. 2011;102(20):9335-44.

5. Guo K, Donose BC, Soeriyadi AH, Prevoteau A, Patil SA, Freguia S, et al. Flame oxidation of stainless steel felt enhances anodic biofilm formation and current output in bioelectrochemical systems. Environ Sci Technol. 2014;48(12):7151-6.

6. Yamashita $T$, Ishida M, Asakawa S, Kanamori $H$, Sasaki H, Ogino A, et al. Enhanced electrical power generation using flame-oxidized stainless steel anode in microbial fuel cells and the anodic community structure. Biotechnol Biofuels. 2016;9

7. Logan BE. Exoelectrogenic bacteria that power microbial fuel cells. Nat Rev Microbiol. 2009;7(5):375-81

8. Seeliger S, Cord-Ruwisch R, Schink B. A periplasmic and extracellular c-type cytochrome of Geobacter sulfurreducens acts as a ferric iron reductase and as an electron carrier to other acceptors or to partner bacteria. J Bacteriol. 1998;180(14):3686-91.
9. Reguera G. Extracellular electron transfer via microbial nanowires. Nature. 2005:435:1098-101.

10. von Canstein H, Ogawa J, Shimizu S, Lloyd JR. Secretion of flavins by Shewanella species and their role in extracellular electron transfer. Appl Environ Microbiol. 2008;74(3):615-23.

11. Bond DR, Lovley DR. Electricity production by Geobacter sulfurreducens attached to electrodes. Appl Environ Microbiol. 2003;69(3):1548-55.

12. Lovley DR, Giovannoni SJ, White DC, Champine JE, Phillips EJP, Gorby YA, et al. Geobacter metallireducens gen. Nov. sp. nov., a microorganism capable of coupling the complete oxidation of organic compounds to the reduction of iron and other metals. Arch Microbiol. 1993;159(4):336-44.

13. Chae K-J, Choi M-J, Lee J-W, Kim K-Y, Kim IS. Effect of different substrates on the performance, bacterial diversity, and bacterial viability in microbial fuel cells. Bioresour Technol. 2009;100(14):3518-25.

14. Logan BE, Regan JM. Electricity-producing bacterial communities in microbial fuel cells. Trends Microbiol. 2006;14(12):512-8.

15. Pant D, Van Bogaert G, Diels L, Vanbroekhoven $K$. A review of the substrates used in microbial fuel cells (MFCs) for sustainable energy production. Bioresour Technol. 2010;101(6):1533-43.

16. Kozich JJ, Westcott SL, Baxter NT, Highlander SK, Schloss PD. Development of a dual-index sequencing strategy and curation pipeline for analyzing amplicon sequence data on the MiSeq Illumina sequencing platform. Appl Environ Microbiol. 2013;79(17):5112-20.

17. Liu H, Ramnarayanan R, Logan BE. Production of electricity during wastewater treatment using a single chamber microbial fuel cell. Environ Sci Technol. 2004;38(7):2281-5.

18. Caporaso JG, Kuczynski J, Stombaugh J, Bittinger K, Bushman FD, Costello EK, et al. QIIME allows analysis of high-throughput community sequencing data. Nat Methods. 2010;7(5):335-6.

19. Edgar RC. Search and clustering orders of magnitude faster than BLAST. Bioinformatics. 2010;26(19):2460-1.

20. DeSantis TZ, Hugenholtz P, Larsen N, Rojas M, Brodie EL, Keller K, et al. Greengenes, a chimera-checked 165 rRNA gene database and workbench compatible with ARB. Appl Environ Microbiol. 2006;72(7):5069-72.

21. Caporaso JG, Bittinger K, Bushman FD, DeSantis TZ, Andersen GL, Knight R. PyNAST: a flexible tool for aligning sequences to a template alignment. Bioinformatics. 2010;26(2):266-7.

22. Wang Q, Garrity GM, Tiedje JM, Cole JR. Naive Bayesian classifier for rapid assignment of rRNA sequences into the new bacterial taxonomy. Appl Environ Microbiol. 2007;73(16):5261-7.

23. Lozupone C, Knight R. UniFrac: a new phylogenetic method for comparing microbial communities. Appl Environ Microbiol. 2005;71(12):8228-35.

24. Tamura K, Dudley J, Nei M, Kumar S. MEGA4: molecular evolutionary genetics analysis (MEGA) software version 4.0. Mol Biol Evol. 2007:24(8):1596-9.

25. Yokoyama H, Ohmori H, Ishida M, Waki M, Tanaka Y. Treatment of cowwaste slurry by a microbial fuel cell and the properties of the treated slurry as a liquid manure. Anim Sci J. 2006;77(6):634-8.

26. Yokoyama H, Waki M, Moriya N, Yasuda T, Tanaka Y, Haga K. Effect of fermentation temperature on hydrogen production from cow waste slurry by using anaerobic microflora within the slurry. Appl Microbiol Biotechnol. 2007;74(2):474-83.

27. Clauwaert P, Aelterman P, Pham TH, De Schamphelaire L, Carballa M, Rabaey K, et al. Minimizing losses in bio-electrochemical systems: the road to applications. Appl Microbiol Biotechnol. 2008:79(6):901-13.

28. Yamashita T, Ookawa N, Ishida M, Kanamori H, Sasaki H, Katayose $Y$, et al. A novel open-type biosensor for the in-situ monitoring of biochemical oxygen demand in an aerobic environment. Sci Rep. 2016;6

29. Pfennig N, Biebl H. Desulfuromonas acetoxidans gen. Nov and sp. nov. new anaerobic, sulfur-reducing, acetate-oxidizing bacterium. Arch Microbiol. 1976;110(1):3-12.

30. Roden EE, Lovley DR. Dissimilatory Fe(iii) reduction by the marine microorganism Desulfuromonas acetoxidans. Appl Environ Microbiol. 1993; 59(3):734-42.

31. Bond DR, Holmes DE, Tender LM, Lovley DR. Electrode-reducing microorganisms that harvest energy from marine sediments. Science. 2002;295(5554):483-5

32. Badalamenti JP, Summers ZM, Chan $\mathrm{CH}$, Gralnick JA, Bond DR Isolation and genomic characterization of 'Desulfuromonas soudanensis WTL', a metal- and electrode-respiring bacterium from anoxic deep subsurface brine. Front Microbiol. 2016;7 
33. Pierra M, Carmona-Martinez AA, Trably E, Godon JJ, Bernet N. Specific and efficient electrochemical selection of Geoalkalibacter subterraneus and Desulfuromonas acetoxidans in high current-producing biofilms. Bioelectrochemistry. 2015;106:221-5.

34. Shibata K, Flores DM, Kobayashi G, Sonomoto K. Direct L-lactic acid fermentation with sago starch by a novel amylolytic lactic acid bacterium. Enterococcus faecium Enzyme Microb Technol. 2007;41(1-2):149-55.

35. Call DF, Logan BE. Lactate oxidation coupled to iron or electrode reduction by Geobacter sulfurreducens PCA. Appl Environ Microbiol. 2011;77(24):8791-4.

36. Nevin KP, Holmes DE, Woodard TL, Hinlein ES, Ostendorf DW, Lovley DR. Geobacter bemidjiensis sp nov and Geobacter psychrophilus sp nov. two novel Fe(III)-reducing subsurface isolates. Int J Syst Evol Microbiol. 2005;55:1667-74.

Submit your next manuscript to BioMed Central and we will help you at every step:

- We accept pre-submission inquiries

- Our selector tool helps you to find the most relevant journal

- We provide round the clock customer support

- Convenient online submission

- Thorough peer review

- Inclusion in PubMed and all major indexing services

- Maximum visibility for your research

Submit your manuscript at www.biomedcentral.com/submit
C) Biomed Central 